Brit. J. industr. Med., 1958, 15, 120.

\title{
THE EFFECTS OF BURSTS OF LOUD NOISE ON A CONTINUOUS VISUAL TASK
}

\author{
BY \\ M. M. WOODHEAD \\ From the Medical Research Council, Applied Psychology Research Unit, Cambridge
}

(RECEIVED FOR PUBLICATION OCTOBER 5, 1957)

Nowadays there are many situations in which men doing mental work with visual material are subjected to brief loud noises heard at irregular intervals from a source close at hand. The study described in this paper was directed at two questions arising from these working conditions. (1) Does the noise interfere with levels of individual efficiency? (2) If any such adverse effects are evident, are the men already making the maximum effort to deal with the distracting noise or could they be warned and encouraged to overcome it ? (It is often useful to detect as far as possible any differences between what people will do and what they can do.)

Research into the psychological effects of loud noise on human performance has generally been concerned with noise presented over a moderately prolonged period of time-a few minutes, an hour, or even a working day. Smith (1950), however, used bursts of sound lasting from 10 to 50 seconds, given at irregular intervals to a group doing paper tests of matching and form-assembling. The intensity was $100 \mathrm{db}$., heard through speakers, one on either side of the test room. The subjects' hearing was not tested, but a control group was used. Test results from the experimental group were quantitatively better and qualitatively worse than the controls, but it was concluded that the differences were negligible for practical purposes. A report from the National Defence Research Council (U.S.A.) in 1942 described two experiments to test the hypothesis that sudden and continued loud sounds, such as encountered in battle, might have harmful effects on the accuracy of tracking and range finding. The sounds lasted two to three minutes, intensities ranged from 100 to $130 \mathrm{db}$. Subjects indicated physiological effects, but test performance did not deteriorate. The present author has not been able to trace any work demonstrating psychological methods of combating the effects of short bursts of sound.

The experiment described below was designed primarily to discover whether brief loud noise affected performance in a visual task. It was followed by a further test to investigate whether alerting and encouraging the operator could assist in combating these effects.

\section{Method}

A task was required in which signals for action appeared very frequently at irregular time intervals so that the noise might occur either at busy or slack periods. The test chosen was a version of the multi-channel test (Mackworth and Mackworth, 1956) in which subjects matched pairs of cards by counting the number of similar symbols on them. There were six items on every card and therefore six comparisons had to be made between each pair of cards. These problems were shown on a vertical screen.

In the present version, 10 stationary cards were arranged in a row along the top of the display window. Beneath these fixed cards were other cards which appeared in 10 channels and moved slowly upwards until they disappeared from view. The entire content of one of these moving cards was fully visible for five seconds, but some part of the card was visible for 20 seconds. Each of these cards had to be compared with its corresponding stationary card. During the four-minute test run there were 70 such comparisons to be made; these occurred irregularly. The display was constantly changing. Sometimes comparisons could be taken slowlywhen perhaps three comparisons were needed and none of these were completely synchronous with each other. Sometimes, however, a burst of activity might mean as many as 10 comparisons showing on the display at the same time, and possibly three of these might arrive almost simultaneously.

A tape recording of an explosive sound was available for the noise and all the noise bursts given were copies of this record. Each burst lasted approximately four seconds and its peak intensity, which was approximately $100 \mathrm{db}$., came on for rather more than one second. Oscillograms of typical bursts are shown in Fig. 1, which indicates the general envelope of a whole burst. Fig. 2 is from a small part of an oscillogram taken on an extended time base. Although the main components of the sound were high in frequency, they were modulated at a low frequency (less than 100 cycles). Fig. 3 shows 

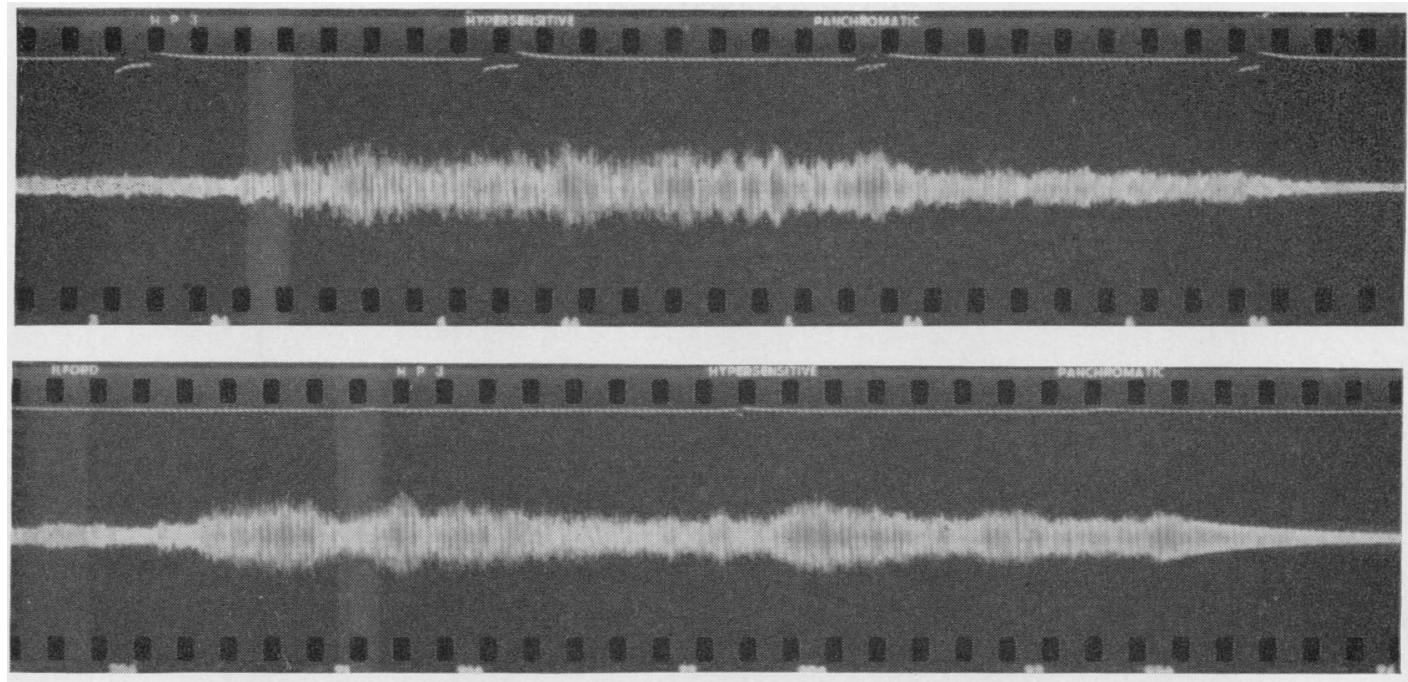

FIG. 1.-Oscillograms of two of the noise bursts. Time base is 1.6 inches per second.

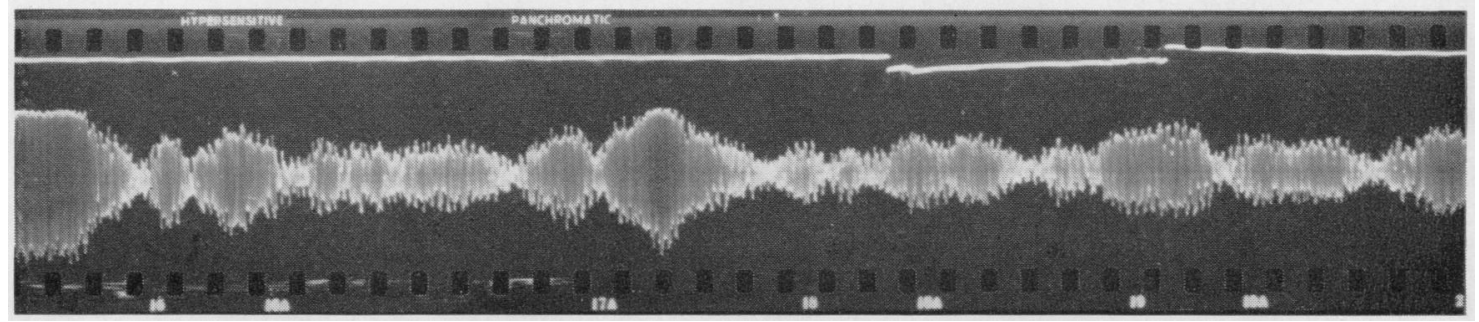

FIG. 2.-A small part of a burst, taken on a time base of 11 inches per second.

an approximate analysis of the sound during the first and second seconds of its duration. At first the main components were centred around 300 cycles, and one second later around 2,000 cycles. For comparison, the spectrum which would have been provided by white noise is included in Fig. 3. The filter used for the approximate frequency analysis was a Wein bridge tuned circuit analogue, and therefore has no definite "band width". It was adjusted, at each tuning point, so that the band width between the $3 \mathrm{db}$. points was one-fifth of the mid-band frequency. The microphone, amplifier, and oscilloscope used for this analysis were not calibrated, and consequently the figures have only relative value.

Four versions of the test film were made:

(1) With four bursts of sound, one at each of two busy periods and one at each of two slack periods;

(2) A repeat of (1), but with the noise at different stages in the visual task.

(3) As for (1) but with a warning light alerting the subject three seconds before each bang.

(4) Silent-no bangs, a control condition.

The purpose of (3) was to discover whether immediate warning cues influenced responses in noisy conditions. All subjects did all versions, in an order determined by a Latin square design. They were instructed and tested individually.
The film was presented by back projection on to a screen set in a booth which was constructed of wood and insulating board, lined with felt, and had a floor area of 4 sq. feet. Sound was introduced through a loudspeaker below the screen and the subject sat at the back of the booth, facing the screen. By this arrangement of subject and speaker in a small damped area it was hoped that the bursts of sound would be uniform for each man regardless of his height and breadth. Subjects were not, however, sitting in a silent room: there was moderate $(70 \mathrm{db}$.) noise from a ventilator fan in the booth wall and the film projector outside the booth. They used a hand microphone and their answers were recorded. The test was presented on magnetic sound film to ensure that the noise bursts occurred always at the same instants during this visual task.

Two groups, $A$ and $B$, each of 12 Naval ratings, were tested. Age ranges were 18 to 25 . All subjects had normal hearing. Audiograms of each man were taken beforehand and again the day after the test; no significant changes were noted.

Test-practice runs were given at both slow and normal speeds, including one noise run at the normal 24 frames per second. The men were sufficiently familiar with the noise bursts for startle to be excluded, yet not familiar enough to have developed an attitude of hearing without 


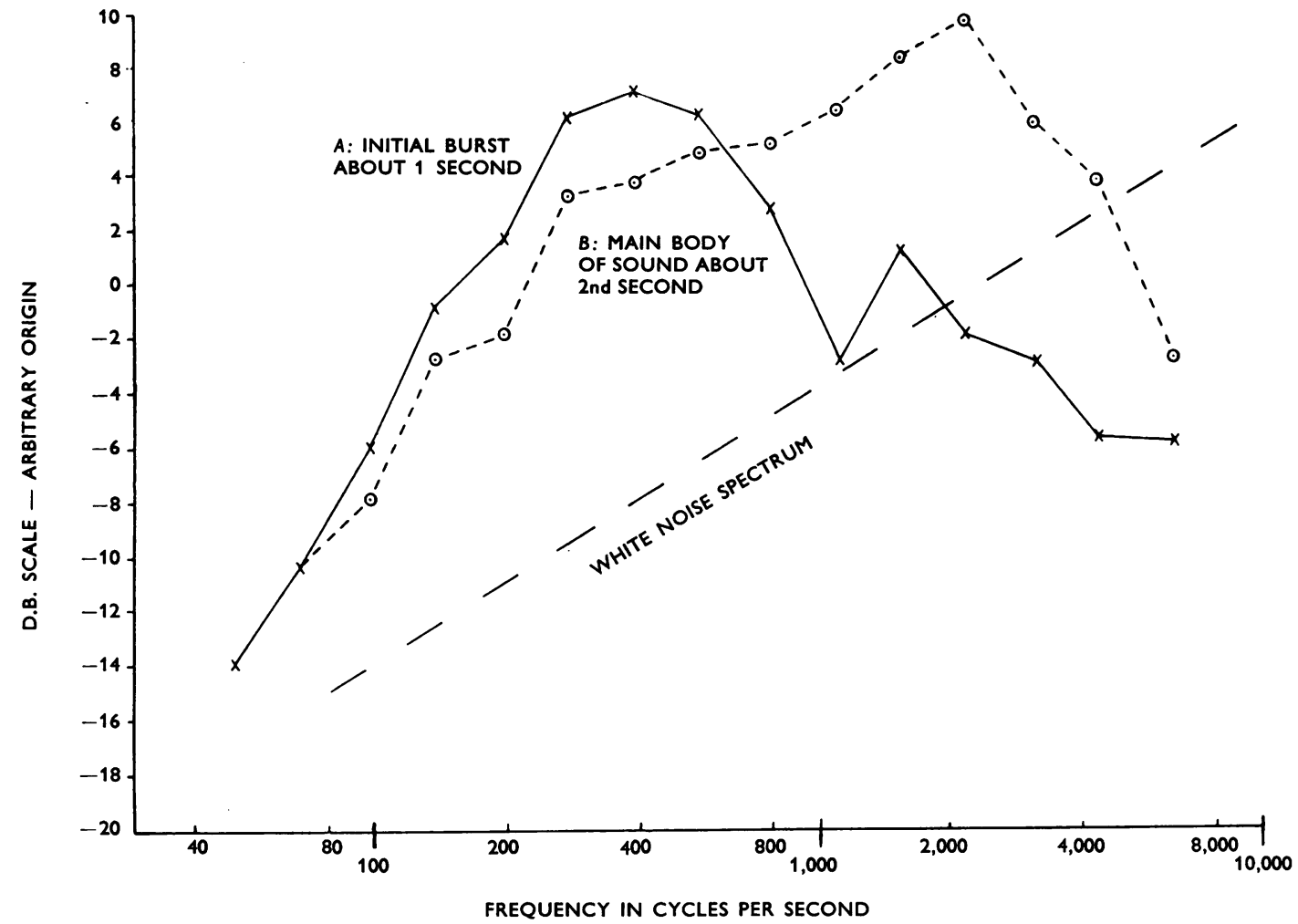

Fig. 3.-Approximate frequency analysis of the sound during first two seconds.

conscious awareness of the sounds. The red warning light was also demonstrated.

There were differences in the instructions given to the two groups. It was hoped that these differences would indicate whether any performance deterioration due to noise was involuntary. Group $A$ received an explanation that the task cards were allied to the flight plans of aeroplanes and the symbols on the cards to relevant pieces of information. The noise was described as resembling the sound of a mild explosion.

Group $B$ received the same explanation, but in addition they had further instructions, encouragement, and day by day knowledge of results. On the third day of their practice runs subjects were informed, "When we were giving this test a few weeks ago, we discovered people did rather less well just after the noise occurred. Either they missed out more cards, or they made more mistakes in the few seconds following a burst of noise. So when you hear a bang, do make a special effort to keep to your normal steady performance, and not to be put off, even for a second". Just before the start of the film subjects were also told, "Remember to keep on as usual immediately after the noise". The actual test was on the fourth day and subjects were again encouraged to maintain their usual performances despite the noise.

When the broad picture of the quality of the taking of decisions by the two groups of subjects was inspected, it was found that the general average scores showed no difference between the noise runs and the silent control runs. (From an analysis of variance there was no significant difference between the overall performances of the two Groups $A$ and $B$, and none between the group results to the four test versions, although there was considerable variation between subjects, with $F$ ratio $32 \cdot 75,23$ and 48 d.f., $P<0.001$.)

A more detailed consideration of the scores, however, brought out some clear-cut differences by an analysis which concentrated on the accuracy shown during the half-minute or so of the task immediately following each bang. This serial analysis of a particular time sample taken from one small key section of the records resembles in some respects the step-by-step analysis of key incidents previously found useful in the quite different problem of the experimental analysis of car driving skill. There the key incident was the corner rather than the bang, and each half-minute analysis included individual performance just before as well as just after the corner (Lewis, 1956).

\section{Results}

1. Key Incident Analysis for Both Groups.-Nineteen of the 24 men tested did better under the silent condition. Four men were better in noise and the 
TABLE 1

EFFECTS OF NOISE FOR ONE TO SIX CARDS AFTER EACH BURST

\begin{tabular}{|c|c|c|c|c|c|c|}
\hline \multirow[b]{2}{*}{ Responses } & \multicolumn{6}{|c|}{ Cards and Times } \\
\hline & $\begin{array}{c}\text { 1st } \\
\text { within } 14 \\
\text { Seconds }\end{array}$ & $\begin{array}{l}\text { 2nd } \\
\text { within } 18 \\
\text { Seconds }\end{array}$ & $\begin{array}{c}\text { 3rd } \\
\text { within } 26 \\
\text { Seconds }\end{array}$ & $\begin{array}{c}\text { 4th } \\
\text { within } 28 \\
\text { Seconds }\end{array}$ & $\begin{array}{l}\text { 5th } \\
\text { within } 31 \\
\text { Seconds }\end{array}$ & $\begin{array}{l}\text { 6th } \\
\text { within } 32 \\
\text { Seconds }\end{array}$ \\
\hline $\begin{array}{l}\text { Total number for each group of subjects } \\
\text { Group } A(N=12): \\
\text { Correct on noise versions, incorrect on silent version } \\
\text { equivalents } \\
\text { Correct on silent version. incorrect on noise version } \\
\text { equivalents } \\
\text { Differences }\end{array}$ & $\begin{array}{r}144 \\
12 \\
37 \\
25\end{array}$ & $\begin{array}{r}144 \\
16 \\
32 \\
16\end{array}$ & $\begin{array}{r}144 \\
26 \\
31 \\
5\end{array}$ & $\begin{array}{r}144 \\
26 \\
23 \\
-3\end{array}$ & $\begin{array}{r}144 \\
15 \\
21 \\
6\end{array}$ & $\begin{array}{r}120 \\
25 \\
25 \\
0\end{array}$ \\
\hline $\begin{array}{l}\text { Group } B(N=12) \text { : } \\
\text { Correct on noise versions, incorrect on silent version } \\
\text { equivalents } \\
\text { Correct on silent version, incorrect on noise version } \\
\text { equivalents } \\
\text { Differences }\end{array}$ & $\begin{array}{r}18 \\
24 \\
6\end{array}$ & $\begin{array}{l}22 \\
37 \\
15\end{array}$ & $\begin{array}{r}21 \\
26 \\
5\end{array}$ & $\begin{array}{l}16 \\
26 \\
10\end{array}$ & $\begin{array}{r}26 \\
26 \\
0\end{array}$ & $\begin{array}{r}25 \\
19 \\
-6\end{array}$ \\
\hline Differences for $A$ and $B$ combined & 31 & 31 & 10 & 7 & 6 & -6 \\
\hline
\end{tabular}

remaining subject was unaffected. These were the results for the card comparisons immediately after each noise burst, compared with their counterparts in the silent control. Better performance usually entailed reporting more signals rather than giving fewer incorrest answers.

2. Detailed Trend Analysis, Group $A$ (No Information).-Table 1 shows the distribution of responses for the first to sixth cards after noise. It is clear that immediately after a burst the performance of Group $A$ was affected. Fig. 4 shows all the correct answers for each of six cards after noise compared with equivalent cards from the silent version. Three times as many correct responses were made to the first of these cards during the silent control compared with those during noise. Similarly for the second card, there were twice as many correct answers in silence compared with during noise (Table 1). Recovery was rapid from these marked changes, and by about 27 seconds after the bang no such difference remained between the noise and silent conditions. It may be noted that the six cards selected followed each other so swiftly that even in the condition without noise the subjects had some difficulty in remaining accurate towards the end of this short series of decisions.

3. Detailed Trend Analysis, Group $B$ (with Information).- The performance of Group $B$ also showed detrimental effects in the noise versions. The differences in responses after noise compared with
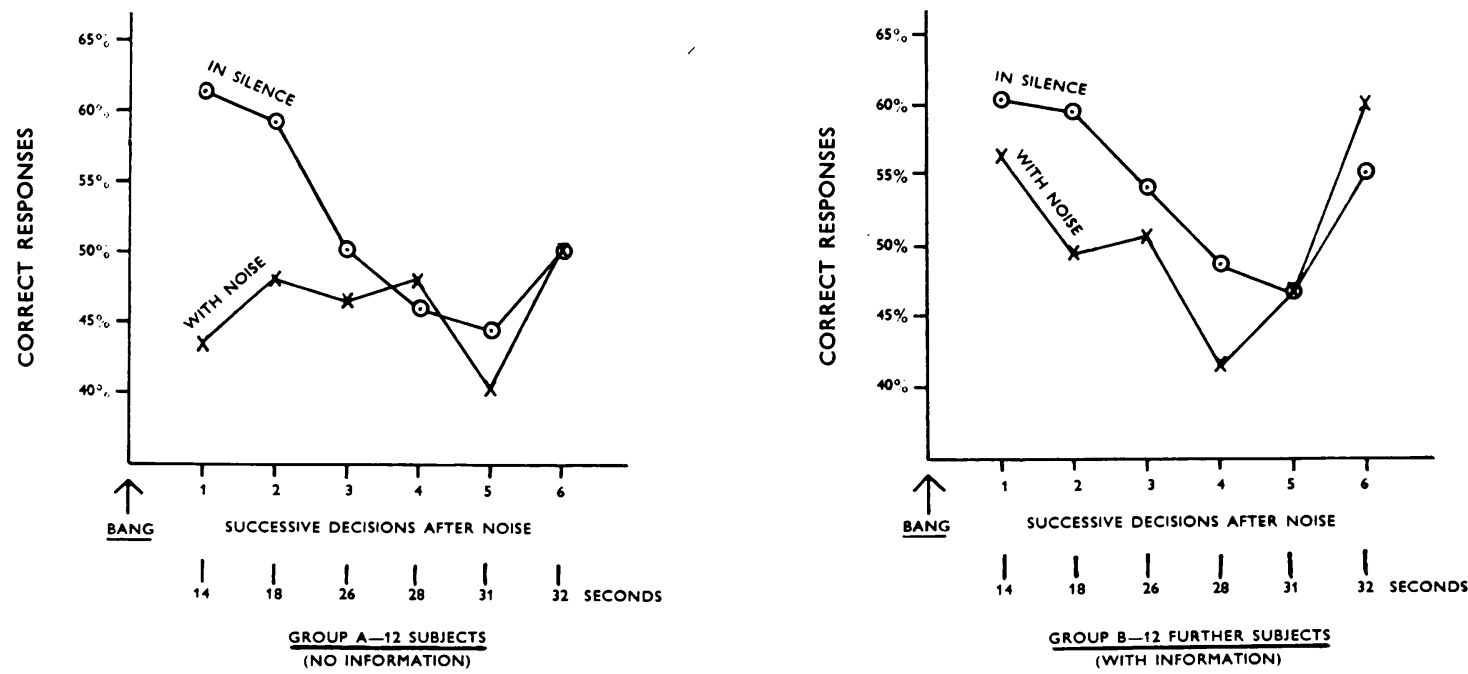

Fig. 4.-Effects of noise: correct responses (percentages) to six decisions after noise and to equivalent cards on the silent version. 
equivalent cards on the silent run were less marked initially, but lasted longer than those shown by Group $A$. Fig. 4 illustrates these results. In the situation where subjects were far more conscious of the distraction danger, this wariness did not prevent deterioration.

4. Effects of Warning Light and Visual Task Demands.-Both groups of subjects showed a trend, not statistically significant at $\mathrm{P}<0.05$ level, towards being less accurate with the warning light; it seemed that the warning was not an aid but may even have been a distraction. Unexpectedly, there were no statistically valid signs of the detrimental effects of noise being greater at busy spells for any given decision.

5. Individual Differences.-Although Group $B$ still failed to produce a statistically significant improvement on the results from the other group, the significant differences between subjects, and the differing group response curves after noise, suggested that individual performances would be interesting.

From individual response curves, only one subject in Group $A$ did not show the adverse effects after hearing the bursts. Four subjects in Group $B$ responded successfully to the revised instructions by maintaining or improving their performance level after noise, although their improved results were insufficient to influence those of the group as a whole. They showed, however, that a third of this group was able to profit from knowledge of possible effects of loud noise (or distraction) and from encouragement to overcome these effects.

6. Recovery Time.-It was feasible for the effects after each noise burst to be assessed in terms of the maximum time available for response. This was done by calculating in seconds the largest of the intervals of time between a bang and the cards immediately after it.

The results demonstrated that effects on performance in the present experimental situation must have occurred in less than 28 seconds for Group $A$ and within 31 seconds for Group $B$ (see Fig. 4). Broadly, it took periods of up to half a minute from the onset of the noise for performance to recover in the sense of returning to the level achieved by the same men without noise.

7. Subjects' Comments.-All 24 subjects were questioned about the test and noise after all testing was over. No one found the visual task intrinsically difficult, but six men referred to the high speed required. Only three found the noise irritating, but other comments on the noise varied from " unduly quiet " through "loud enough" to "could still hear myself think, which is all that matters". No physical symptoms were reported. Five subjects found the red warning light more distracting than the bursts of noise. Opinions were evenly divided on the need for extra concentration during noise.

Although no special emphasis is placed on these subjective reactions to the test and the noise, it is worth noting that all the men assumed that this general problem of effects of loud noise heard during pressure of work was a problem which they were constantly experiencing as Naval personnel.

\section{Discussion}

The test conditions for Group $A$ left undecided the question whether subjects were merely reluctant or actually unable to keep responding normally during and immediately after the noise. The revised conditions for Group $B$ excluded the possibility of the men succumbing to the harassing effects of the bangs simply because they were unaware of being harassed.

It seems reasonable that people may feel disinclined to speak their responses during loud bangs, even when particularly motivated to do so. But here the brevity of the noise effects and the rapid rate of recovery indicated that the subjects in both groups were trying to keep up with the visual display. There is little evidence to support the idea of a simple reluctance to respond.

It appears that most of those tested were actually unable to avoid showing some effects from brief loud noises whilst doing a task of the decision-taking type. On the other hand, the performances of the five exceptional subjects make it clear that there are men who have the ability to combat these effects.

It might be thought that if all the subjects kept to their fastest working rate throughout, they would then have time to suspend their task briefly around noisy periods without missing any signals. There were slack periods of the test when few decisions had to be made and subjects should have been able to pause, without missing a signal, at the time when distraction occurred. Instead they reduced their rate of work at these periods, not leaving themselves any convenient gaps, and therefore even at slow signal input rates, their attention was sustained and could be disturbed by noise.

The test was not only varied by differing instructions and rate of work, but also by the warning light system which was found to be unhelpful. Variations in the task situation did not, therefore, alter the overall results as they would certainly have done in operations such as watchkeeping. It is apparent that the noise distraction was the dominant factor. If the short reaction to bursts of noise is a fundamental one, it may be independent of current activity of the kind required in the present experiment and not due to the shock of an unusual noise for which 
the operator is entirely unprepared. Despite his positive efforts he is unable to act normally-unless he belongs to the minority quickly reacting group. One hypothesis is that when subjected to noise of this type a person's perceptual mechanism is less affected than his response mechanism. (In this connexion the evidence of Coleman and Krauskopf (1956) indicates that the visual function is not likely to be disturbed by noise intensities around $100 \mathrm{db}$.)

From the point of view of practical application, it cannot be expected that the sustained effort expended on four-minute tests could be kept up for very long. Four brief noises at a maximum of $100 \mathrm{db}$. here prevented most of the subjects from maintaining during a short period the standard of work they had established when the noises were absent. Therefore they could not be expected to maintain it during longer periods. It may be that sufficient familiarity with a regularly occurring noise eventually overrules any distracting effects. But in those operational situations where there is intermittent loud noise, it does appear that there is a danger of assuming that activity will be normal and needs no extra check for accuracy. Supervisors and operators should be aware of the distracting hazards of this kind of loud noise.

A further experiment is now in progress, in which a shorter and louder noise is used than the one described above. Bursts repeating at brief intervals have also been introduced as another aspect of the problem of loud noise. It would be of great interest also to compare the performances of men who are exposed to intermittent noise every working dayperhaps in industrial conditions-with performances from men who are exposed to it only occasionally.

\section{Conclusions}

From the significant results of a group of young Naval ratings it may be inferred that some, at least, of those men who must rapidly take a series of quick decisions within range of short bursts of a moderately loud noise (to which they are accustomed but not completely adapted) may have a temporary loss of working efficiency lasting up to half a minute after each noise. This trend towards some loss of efficiency can occur whether or not the men are made aware of the possibility of deterioration. There will probably be a tendency to miss signals altogether rather than to report them incorrectly.

It will be worth while acquainting all men who have to respond to continuous visual signals against a background of occasional loud noises of the particular alertness needed to avoid missing signals immediately after hearing the noise. This information will not cause further deterioration but will enable a minority to overcome the distracting effects.

\section{Summary}

The effects of short bursts of loud sound on the performance of men doing a visual matching task are described. The task ran for four minutes and four bursts of noise were given at irregularly-spaced intervals during that time. Each of these bursts lasted four seconds and reached a peak intensity of $100 \mathrm{db}$., the noise being widely distributed over the frequency spectrum.

Two groups of subjects were tested. One group was given more information about the test than the other and also received verbal encouragement and knowledge of results. The aim of these apparently more favourable testing conditions was to discover whether any deterioration in performance after noise could be lessened by alerting the men to the danger and encouraging them to overcome it.

The main conclusion is that bursts of loud noise heard by men engaged on a visual task caused immediate deterioration in the performance of most of them, with complete recovery during the next half-minute.

The results also demonstrate a general tendency for performance of this type of work to deteriorate immediately after brief loud noise even when operators are aware of this possibility and are attempting to deal with it. In the experiment small variations in the task, such as a warning light, did not prevent deterioration. Prior verbal alerting and instruction to some operators enabled only a third of these to avoid the detrimental effects.

The author wishes to express her gratitude to Dr. N. H. Mackworth, Director, M.R.C. Applied Psychology Research Unit, for his guidance and interest in this study; and to Mr. D. Broadbent, Dr. A Carpenter, and Mr. D. Simmonds for their considerable technical help and advice.

\section{REFERENCES}

Coleman, P. D., and Krauskopf, J. (1956). The Influence of High Intensity Noise on Visual Thresholds. Army Medical Research

Laboratory Report No. 222. Fort Knox, U.S.A
Lewis, R. E. F. (1956). Brit. J. industr, Med., 13, 131.

Mackworth, J. F., and Mackworth, N. H. (1956). Amer. J. Psychol. $69,26$.

National Defence Research Council Report 37 (1942). Effects of Loud Sounds on the Accuracy of Azimuth Tracking and of Stereoscopic Range Finding. Washington.

Smith, K. R. (1950). Intermittent Loud Noise and Mental Performance. U.S.A.F. Technical Report No. 6368. Washington. 